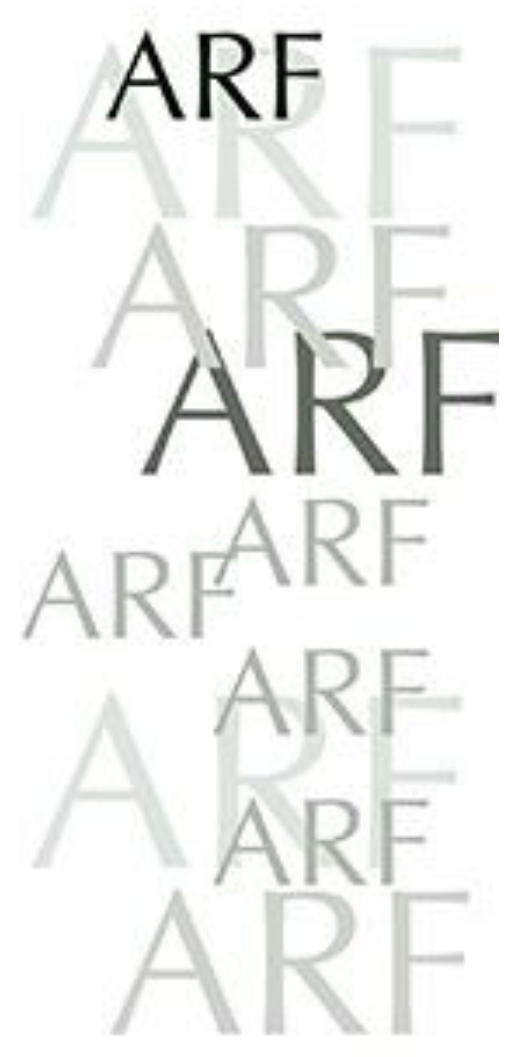

\title{
Preface by Editor-in-Chief
}

\author{
Kimmo Lapintie \\ Aalto University \\ kimmo.lapintie@aalto.fi
}

The key terms of this issue - architecture and the city as a home - have been paradoxical ever since Le Corbusier defined the home as a 'Machine à habiter', a machine for living in. The rationalist understanding of living, divided into measurable and normalised activities like sleeping, eating and socializing, has always been confronted with the romantic and emotional meanings attached to homes. The connotations of stability, security and attachment are at odds with the abstract biopolitical machine for reproduction. In geography, Yi-Fu Tuan juxtaposed place and space with similar characteristics: "From the security and stability of place we are aware of the openness, freedom, and threat of space, and vice versa. Furthermore, if we think of space as that which allows movement, then place is pause; each pause in movement makes it possible for location to be transformed into place." (Tuan, 1977; 2011, p. 6).

In her keynote lecture, Karine Dupre used the narrative technique to describe her journey through various places of residence in several countries - indeed pauses, instead of stable places that one would leave and come 'back home'. Modern global nomadism challenges the idea of stability; not even physical and mental investments, such as renovating, designing or building are sufficient to keep one in the same place, if feelings of security and sought-for social environments are not 'in place'. The home is not a building, rather it is a process of 'home-making'.

On the other hand, the inclusion of time is not the only needed extension to our thinking. The phenomenon of residential multi-locality rejects the very idea of one home - either permanent or temporary - that our official statistics is still based on. Cities, regions and countries as mobility networks or - to be more exact - as 'modality networks' offering various coexistent possibilities, challenges our territorial understanding of urban planning and architectural design.

As the extreme opposite of the life of multi-local elites we of course have homelessness, multi-locality without any central and fixed place. In her article, Hannah Strothmann points out that homelessness and the consecutive living 'on the move' is an alternative way of using the city as a whole as a place of residence, involuntarily resisting its foundations in property ownership. Homelessness is conceptually total negativity, without identity of its own, and thus it is subjected to the age-old ideology against vagabondage and promoting of sedentary lifestyles.

Issues like nomadism and homelessness also challenge the tradition of conceptualizing architecture mainly as objects of perception and aesthetic appreciation. Since the city around homes - and as a home - in inherently political, this perspective needs to be addressed in architectural research too. In her case study of Quarticciolo, one of the fascist-era suburbs around the city of 
Rome, Minna Kulojärvi discusses three existing narratives that are used to identify such neighbourhoods: as models of the rationalist tendencies to segregate and control, as models of the resistance against fascism, and as models of avant-garde rationalist modern architecture. Whereas the first two narratives are openly political, the third is often given an a-political reading, detaching it from its societal context.

These very different perspectives to the theme illustrate the variety of approaches available: the homes as voluntary pauses of life-long home-making, the city as a home for the most vulnerable, and home as a rational means in housing policy and even as symbols of power regimes and machines of control. These and many other questions were discussed in the 11th Symposium of Architectural Research in Finland, and the articles in this issue are selected from the papers presented there. Instead of editing a thematic issue, however, we have asked scholars to rethink the meaning of home in the light of their own research approaches.

\section{Reference}

Tuan, Yi-Fu (1977; 2011). Space and Place. The Perspective of Experience. Seventh printing. 